\title{
Sanguinarine Attenuates Collagen-Induced Platelet Activation and Thrombus Formation
}

\author{
Dan Shu 1,2,3 (D), Ying Zhu 1,2, Meng Lu ${ }^{1,2}$, Ao-Di He ${ }^{4,5}$, Jiang-Bin Chen ${ }^{1}$, Ding-Song Ye ${ }^{1}$, Yue Liu ${ }^{1,2}$, \\ Xiang-Bin Zeng ${ }^{1,2}$, Rong Ma ${ }^{1}$ and Zhang-Yin Ming ${ }^{1,2,6, *}$
}

1 Department of Pharmacology, School of Basic Medicine, Tongji Medical College of Huazhong University of Science and Technology, 13 Hangkong Road, Wuhan 430030, China; d201781151@hust.edu.cn (D.S.); d201881246@hust.edu.cn (Y.Z.); d201981341@hust.edu.cn (M.L.); u201610406@hust.edu.cn (J.-B.C.); u201610404@hust.edu.cn (D.-S.Y.); m201875087@hust.edu.cn (Y.L.); m201975292@hust.edu.cn (X.-B.Z.); marong@hust.edu.cn (R.M.)

2 The Key Laboratory for Drug Target Research and Pharmacodynamic Evaluation of Hubei Province, 13 Hangkong Road, Wuhan 430030, China

3 College of Pharmacy, Xiangnan University, 889 Chenzhou Avenue, Chenzhou 423000, China

4 Department of Physiology, School of Basic Medicine, Huazhong University of Science and Technology, Wuhan 430030, China; adhe@hust.edu.cn

5 Wuhan Center for Brain Science, Huazhong University of Science and Technology, Wuhan 430030, China

6 Tongji-Rongcheng Center for Biomedicine, Huazhong University of Science and Technology, Wuhan 430030, China

* Correspondence: zyming@hust.edu.cn; Tel.: +86-27-83650710

check for updates

Citation: Shu, D.; Zhu, Y.; Lu, M.; He, A.-D.; Chen, J.-B.; Ye, D.-S.; Liu, Y.; Zeng, X.-B.; Ma, R.; Ming, Z.-Y.

Sanguinarine Attenuates

Collagen-Induced Platelet Activation and Thrombus Formation.

Biomedicines 2021, 9, 444. https://

doi.org/10.3390/biomedicines 9050444

Academic Editor: Anand

Prakash Singh

Received: 25 February 2021

Accepted: 7 April 2021

Published: 21 April 2021

Publisher's Note: MDPI stays neutral with regard to jurisdictional claims in published maps and institutional affiliations.

Copyright: (C) 2021 by the authors. Licensee MDPI, Basel, Switzerland This article is an open access article distributed under the terms and conditions of the Creative Commons Attribution (CC BY) license (https:// creativecommons.org/licenses/by/ $4.0 /)$
Abstract: Sanguinarine, a benzophenanthridine alkaloid, has been described to have an antiplatelet activity. However, its antithrombotic effect and the mechanism of platelet inhibition have not thoroughly been explored. The current study found that sanguinarine had an inhibitory effect on thrombus formation. This inhibitory effect was quite evident both in the flow-chamber assays as well as in a murine model of $\mathrm{FeCl}_{3}$-induced carotid artery thrombosis. Further investigations also revealed that sanguinarine inhibited the collagen-induced human platelet aggregation and granule release. At the same time, it also prevented platelet spreading and adhesion to immobilized fibrinogen. The molecular mechanisms of its antiplatelet activity were found to be as follows: 1 . Reduced phosphorylation of the downstream signaling pathways in collagen specific receptor GPVI (Syk-PLC $\gamma 2$ and PI3K-Akt-GSK3 3 ); 2. Inhibition of collagen-induced increase in the intracellular $\mathrm{Ca}^{2+}$ concentration $\left(\left[\mathrm{Ca}^{2+}\right] \mathrm{i}\right) ; 3$. Inhibition of integrin $\alpha \mathrm{IIb} \beta 3$ outside-in signaling via reducing $\beta 3$ and Src (Tyr-416) phosphorylation. It can be concluded that sanguinarine inhibits collagen-induced platelet activation and reduces thrombus formation. This effect is mediated via inhibiting the phosphorylation of multiple components in the GPVI signaling pathway. Current data also indicate that sanguinarine can be of some clinical value to treat cardiovascular diseases involving an excess of platelet activation.

Keywords: sanguinarine; antithrombotic; platelet; glycoprotein VI pathway; integrin $\alpha \operatorname{IIb} \beta 3$

\section{Introduction}

Platelets are discoid, anucleate cells that are continuously produced by megakaryocytes. They are key factors during hemostasis and thrombosis, along with other physiological and pathological processes [1]. Epidemiological investigations indicate that several risk factors of thrombosis are related to high platelet activity and excessive activation of endothelial cell procoagulant functions. Moreover, abnormal platelet adhesion, aggregation, granule release and spreading can be the basis of thrombotic disease [2]. The subendothelial matrix proteins collagen and von Willebrand factor (vWF) are exposed by the damages to endothelium. Thrombus is initiated by adhesion of platelet to collagen (via GPVI) and vWF (via GPIb-V-IX) [1]. Syk-PLC 22 and PI3K-Akt signaling pathways are involved in collagen-activated platelets. Then it results in mobilization of cytoplasmic calcium, platelet 
shape change and granule release [3-5]. Platelets release a few soluble agonists, including ADP and thromboxane A2. Thus, intensifying activated platelets attracts more platelets from circulation to enlarge the thrombus [6]. Arterial thrombosis from platelet activation leads to the acute severe symptoms of heart disease and thrombotic stroke [7]. Currently, the most effective and clinically recommended antiplatelet drugs are cyclooxygenase- 1 , platelet adenosine diphosphate (ADP) receptor $\mathrm{P}_{2} \mathrm{Y}_{12}$ and integrin $\alpha \mathrm{Ilb} \beta 3$ inhibitors [8]. However, all the recommended treatments do have a few limitations, specifically in singletarget treatments. These limitations lead to drug resistance and poor selectivity, which in turn increase the risk of irreversible bleeding [9]. In recent years, more researchers have focused on the antiplatelet and antithrombotic activities of natural compounds in Chinese herbal medicine [10].

Sanguinarine, a benzophenanthridine alkaloid, is found in a variety of plants, including Macleaya cordata, Herba sanguinariae and Lysimachia platyphylla [11]. As an FDA-approved compound, it is used as a health product to inhibit the growth of dental plaque [12]. Other biological and pharmacological activities of sanguinarine include anti-inflammatory, antioxidant and antitumor. Recently, these activities have attracted greater attention from researchers around the world [13]. A study by Jeng reported that the effect of sanguinarine on platelet activation in vitro is related to the production of thromboxane and cAMP [14]. However, the role of sanguinarine in platelet inhibition and thrombosis is not completely elucidated to date. Here, we report that sanguinarine attenuates collagen-induced platelet activation and thrombus formation by targeting the GPVI pathway, intracellular $\mathrm{Ca}^{2+}$ mobilization and integrin $\alpha \mathrm{IIb} \beta 3$-mediated "outside-in" signal transduction.

\section{Materials and Methods}

\subsection{Chemicals and Reagents}

Sanguinarine (13-methyl(1,3) benzodioxolo (5,6-c) -1,3-dioxolo(4,5-i) phenanthridinium), (HPLC $\geq 98 \%$, SA, Figure 1) (Absin, Shanghai, China), was dissolved in $0.1 \%$ DMSO (final concentration). The EDTA, prostaglandin E1(PGE1) and bovine serum albumin (BSA) were obtained from Sigma (St. Louis, MO, USA). The CHRONO-LUME reagent and collagen were acquired from Chrono-Log Corp. (Havertown, PA, USA). The collagen-related peptide was obtained from Dr. Newman's lab (Blood Center of Wisconsin, Milwaukee, WI, USA). The FITC-conjugated anti-CD62P (P-selectin) antibody and FITC-conjugated anti-PAC$1(\alpha \mathrm{IIb} \beta 3)$ antibody were purchased from Biolegend (San Diego, CA, USA). The Fluo-3AM was purchased from MCE (Shanghai, China). The CellTrace Calcein Green was purchased from Invitrogen (Carlsbad, CA, USA). The anti-phospho-PI3K(Ser1070), anti-PI3K, antiphospho-Akt(Ser473), anti-phospho-GSK3 $\beta$ (Ser9), anti-phoshpo-PLC $\gamma 2$ (Tyr1217), anti$\beta 3$, anti-phospho- $\beta 3$ (Tyr474), anti-Src, anti-phospho-Src (Tyr416) and anti-phospho-Syk (Tyr525/526) antibodies were purchased from Cell Signaling Technology (Beverly, MA, USA). The anti-Syk, anti-PLC $\gamma 2$, anti-Akt and antil-GSK3 $\beta$ were acquired from Santa Cruz Biotechnology (Dallas, TX, USA).

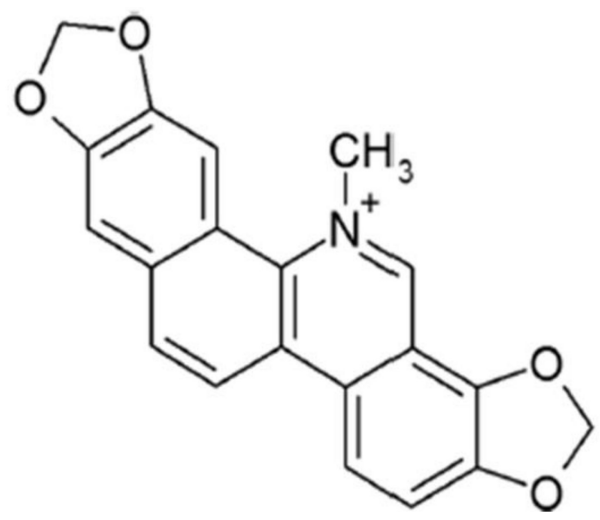

Figure 1. Chemical structure of sanguinarine. 


\section{2. $\mathrm{FeCl}_{3}$-Induced Carotid Arterial Injury Thrombosis Model}

To determine the antithrombotic effect of sanguinarine, we measured the occlusion time in the $\mathrm{FeCl}_{3}$-induced carotid arterial injury thrombosis model, which has been shown to cause substantial endothelium damage with exposure of underlying collagens [15]. The protocol was adapted from previously published work with minor changes [16]. C57BL/6 mice (8-12 weeks old) were obtained from Hubei Experimental Animal Research Center (Wuhan, Hubei, China). The mice experiments were evaluated and permitted by the Ethics Committee for experimental animals, Tongji Medical College. Sanguinarine $(5 \mathrm{mg} / \mathrm{kg}$ or $10 \mathrm{mg} / \mathrm{kg}$ ) was given intragastrically $24 \mathrm{~h}, 12 \mathrm{~h}$ and $2 \mathrm{~h}$ before modeling. The mice were given anesthetics by intraperitoneal injection of pentobarbital sodium before the surgical operations in which their carotid arteries were exposed. A Doppler flow probe (Transonic, TS420, UK) was used to measure the baseline blood flow in the proximal carotid artery. A $2 \mathrm{~mm}$ strip of filter paper saturated with $10 \%$ ferric chloride was introduced into the carotid artery adventitial surface for $1 \mathrm{~min}$. Then the filter paper was removed, and blood flow through the carotid artery was then observed carefully for $45 \mathrm{~min}$ or until $95 \%$ vessel occlusion was achieved.

\subsection{Bleeding-Time Tests}

The bleeding time of the mouse tails was measured as described previously [17]. Sanguinarine ( $5 \mathrm{mg} / \mathrm{kg}$ or $10 \mathrm{mg} / \mathrm{kg}$ ) was given intragastrically $24 \mathrm{~h}, 12 \mathrm{~h}$, and $2 \mathrm{~h}$ prior to the surgery. Tails were cut $5 \mathrm{~mm}$ from the tip with a razor blade, then the tails were immediately immersed in $37^{\circ} \mathrm{C}$ saline, and the time to cessation of bleeding was recorded. A stable cessation of bleeding was established when there was no rebleeding for more than $1 \mathrm{~min}$.

\subsection{Human Platelet Preparation}

The human platelets were isolated from freshly drawn venous blood, collected from 15 healthy volunteers ( 8 males and 7 females, 18-25 years old) who had not taken any drugs that could affect platelet function in the previous 2 weeks. The study design was approved by the relevant ethics committees. The washed platelets were arranged and organized as reported previously [4,5]. In brief, human blood was drawn from the cubital vein without stasis into siliconized vacutainers that contained 1:9 $(v / v) 3.8 \%$ trisodium citrate. Platelets were rinsed with Tyrode's buffer $(137 \mathrm{mM} \mathrm{NaCl}, 13.8 \mathrm{mM} \mathrm{NaHCO}$, $5.5 \mathrm{mM}$ glucose, $2.5 \mathrm{mM} \mathrm{KCl}, 20 \mathrm{mM}$ HEPES, $\left.0.36 \mathrm{mM} \mathrm{NaH}_{2} \mathrm{PO}_{4}, \mathrm{pH} 7.4\right)$ containing $1 \mu \mathrm{M}$ PGE1 and $2.5 \mathrm{mM}$ EDTA, and then placed in suspension in Tyrode's buffer not containing PGE1 or EDTA at a final concentration of $3 \times 10^{8} / \mathrm{mL}$. All preparations for human platelets were conducted at room temperature. Platelets that were resuspended needed to rest for at least $30 \mathrm{~min}$ before experiment.

\subsection{Platelet Aggregation and ATP Release Assay}

Platelet aggregation and ATP release assays were executed according to the previous reports [5]. The platelet pellet was resuspended in Tyrode's buffer, and the concentration was then adjusted to $3 \times 10^{8} / \mathrm{mL}$ for the aggregation studies. Later, the platelets were preincubated with either sanguinarine alone or DMSO (control) for $10 \mathrm{~min}$ at $37^{\circ} \mathrm{C}$. Prior to individual agonist stimulations, $\mathrm{CaCl}_{2}(1 \mathrm{mM})$ was added. Using a luciferin-luciferase reagent (CHRONO-LUME, Chrono-Log, Havertown, PA, USA), the release of ATP was measured. The ATP release was documented and examined with the Aggregolink software (Chrono-Log, Havertown, PA, USA).

\subsection{Flow Cytometric Analysis}

Washed human platelets were preincubated with sanguinarine $(1,2.5$ and $5 \mu \mathrm{M})$ or DMSO (control) for $10 \mathrm{~min}$ before incubating with collagen $(2 \mu \mathrm{g} / \mathrm{mL})$ at $37^{\circ} \mathrm{C}$ for $5 \mathrm{~min}$. The binding of FITC-conjugated anti-CD62P (P-selectin) antibody and FITC-conjugated anti-PAC-1 $(\alpha \mathrm{IIb} \beta 3)$ antibody to platelets $\left(5 \times 10^{7} / \mathrm{mL}\right)$ was performed by incubation in 
the dark at room temperature for $15 \mathrm{~min}$, and was later evaluated with a BD Biosciences flow cytometer (San Jose, CA, USA).

\subsection{Platelet Adhesion on the Collagen-Coated Surface under Flow}

The experiments were performed as described previously with minor modifications [18]. The Bioflux plates (Bioflux 1000Z, Fluxion Biosciences Inc., South San Francisco, CA, USA) were covered with $100 \mu \mathrm{g} / \mathrm{mL}$ collagen overnight at $4{ }^{\circ} \mathrm{C}$. Washed human platelets were labeled with CellTrace Calcein Green $\left(0.34 \mu \mathrm{M}\right.$, at $37^{\circ} \mathrm{C}$ for $\left.30 \mathrm{~min}\right)$ and then incubated with DMSO (control) or sanguinarine $(1,2.5$ and $5 \mu \mathrm{M})$ for $10 \mathrm{~min}$. The mixture of labeled platelets and washed red blood cells (with a hematocrit of about $40 \%$ ) and $\mathrm{CaCl}_{2} / \mathrm{MgCl}_{2}(75 \mathrm{mM} / 37.5 \mathrm{mM})$ was perfused through Bioflux plates at a wall shear rate of $2000 \mathrm{~s}^{-1}$ for $5 \mathrm{~min}$. To detect platelet adhesion, a $10 \times$ long-working-distance objective was utilized for fluorescence and transmitted light microscopy. The formation of thrombus was detailed using an inverted epifluorescence microscope (Zeiss Microscope, Shanghai, China) integrated with the software. The platelet coverage was then evaluated based on the intensity and coverage area with the Bioflux Montage software (Fluxion Biosciences Inc., South San Francisco, CA, USA).

\subsection{Calcium Signaling}

Intracellular $\mathrm{Ca}^{2+}$ flux was measured by flow cytometry [19]. Washed human platelets $\left(5 \times 10^{7} / \mathrm{mL}\right)$ were labeled with $1 \mu \mathrm{M}$ Fluo-3AM at $37^{\circ} \mathrm{C}$ for $30 \mathrm{~min}$, then incubated with sanguinarine $(1,2.5$ and $5 \mu \mathrm{M}$ ) or DMSO (control) for $10 \mathrm{~min}$. After collecting a baseline reading for $20 \mathrm{~s}$, collagen $(2 \mu \mathrm{g} / \mathrm{mL})$ and $2 \mathrm{mM}$ extracellular calcium were added to the FACS tube, and the change in fluorescence intensity was recorded on a BD Biosciences flow cytometer (BD Biosciences, Franklin Lakes, NJ, USA) and analyzed using Flowjo V10 (BD Biosciences, Franklin Lakes, NJ, USA). The fitting curve was plotted using SigmaPlot software 14.0 (Systat Software, Inc., San Jose, CA, USA).

\subsection{Platelet Spreading on Immobilized Fibrinogen}

Platelet spreading on the surfaces covered with fibrinogen was conducted as described previously [20]. Platelet adhesion was observed using a fluorescence microscope (OLYMPUS BX51, Olympus (China) Co., Ltd., Beijing, China), images were obtained using an OLYMPUS CCD camera, then the spreading area of individual platelets was analyzed with Image J software 1.8.0 (NIH open source, Bethesda, MD, USA).

\subsection{Immunoblot Analysis}

For the detection of phosphorylated proteins, aggregated or spreading platelets underwent lysis by adding an equal volume of $2 \times$ lysis buffer (30 mM HEPES, $300 \mathrm{mM}$ $\mathrm{NaCl}, 20 \mathrm{mM}$ EGTA, $0.2 \mathrm{mM} \mathrm{MgCl} 2,2 \%$ Triton $X-100,2 \times$ protease, $2 \times$ phosphatase inhibitor cocktails) into the reactions. The lysates were separated by SDS-PAGE ( $8 \%$ Bis Tris Gel) and transferred onto a PVDF membrane (Invitrogen). Then the membrane was incubated with the following antibodies: pSyk (Tyr525/526), Syk, pPLC $\gamma 2$ (Tyr1217), PLC $\gamma 2$, pPI3K(Ser1070), PI3K, pAkt(Ser473), Akt, pGSK3 $\beta$ (Ser9), GSK3 $\beta$, p $\beta 3$ (Tyr474), $\beta 3$, pSrc (Tyr416), Src. GAPDH served as the internal standard. Protein bands were visualized by an enhanced chemiluminescence assay kit (Thermo Fisher Scientific (China) Co., Ltd., Shanghai, China). Signal quantification was performed on raw images using Image J software 1.8.0 (NIH open source, Bethesda, MD, USA).

\subsection{Statistical Analysis}

Data were analyzed using Graph Pad Software 7.0 and the results were expressed as the means \pm SEM, while the variance of the data was also used to evaluate the data. A two-tailed unpaired comparison test using a t-test was adopted to analyze the difference between two groups. One-way analysis of covariance (ANOVA) was utilized to compare more than two groups. $p<0.05$ was considered significant. 


\section{Results}

\subsection{Sanguinarine Inhibits Arterial Thrombosis In Vivo and In Vitro}

To check sanguinarine antithrombotic effect in vivo, we used the $\mathrm{FeCl}_{3}$ injury-induced carotid thrombosis model. A doppler flow meter detected the vessel occlusion time. While sanguinarine has great liver toxicity by intravenous and intraperitoneal injection, it is relatively safe for intragastric administration. The $\mathrm{LD}_{50}$ of sanguinarine is less than $200 \mathrm{mg} / \mathrm{kg}$ by intragastric administration [21]. Its $\mathrm{T}_{\text {MAX }}$ is $2 \mathrm{~h}$, and it completely eliminated from the plasma and liver after $24 \mathrm{~h}$ [11]. Sanguinarine $(5 \mathrm{mg} / \mathrm{kg}$ or $10 \mathrm{mg} / \mathrm{kg})$ was given intragastrically $24 \mathrm{~h}, 12 \mathrm{~h}$ and $2 \mathrm{~h}$ before modeling. The results indicated that the average occlusion times in $5 \mathrm{mg} / \mathrm{kg}$ and $10 \mathrm{mg} / \mathrm{kg}$ groups were $1166 \mathrm{~s}$ and $1427 \mathrm{~s}$, respectively, which were much longer than that in the control group (660 s) (both $p<0.05$ ) (Figure 2a). Nevertheless, the tail bleeding time was not prolonged in the sanguinarine treatment group (Figure 2b). This implies that the drug did not cause bleeding at the antithrombotic dose. Under normal and pathological conditions in vivo, the shear force exerted by blood laminar flow is considered an important environmental factor during platelet activation and thrombosis. [22]. To further demonstrate sanguinarine antithrombotic effect in clinic, a microfluidic system (Bioflux 1000Z, Fluxion Biosciences Inc., South San Francisco, CA, USA) was used to simulate the adhesion of human platelets to collagen matrix under high shear stress of arterial stenosis in vivo. We found that $1 \mu \mathrm{M}, 2.5 \mu \mathrm{M}$ and $5 \mu \mathrm{M}$ sanguinarine significantly reduced the adhesion area of platelets to the collagen matrix under arterial shear (Figure 2c,d).
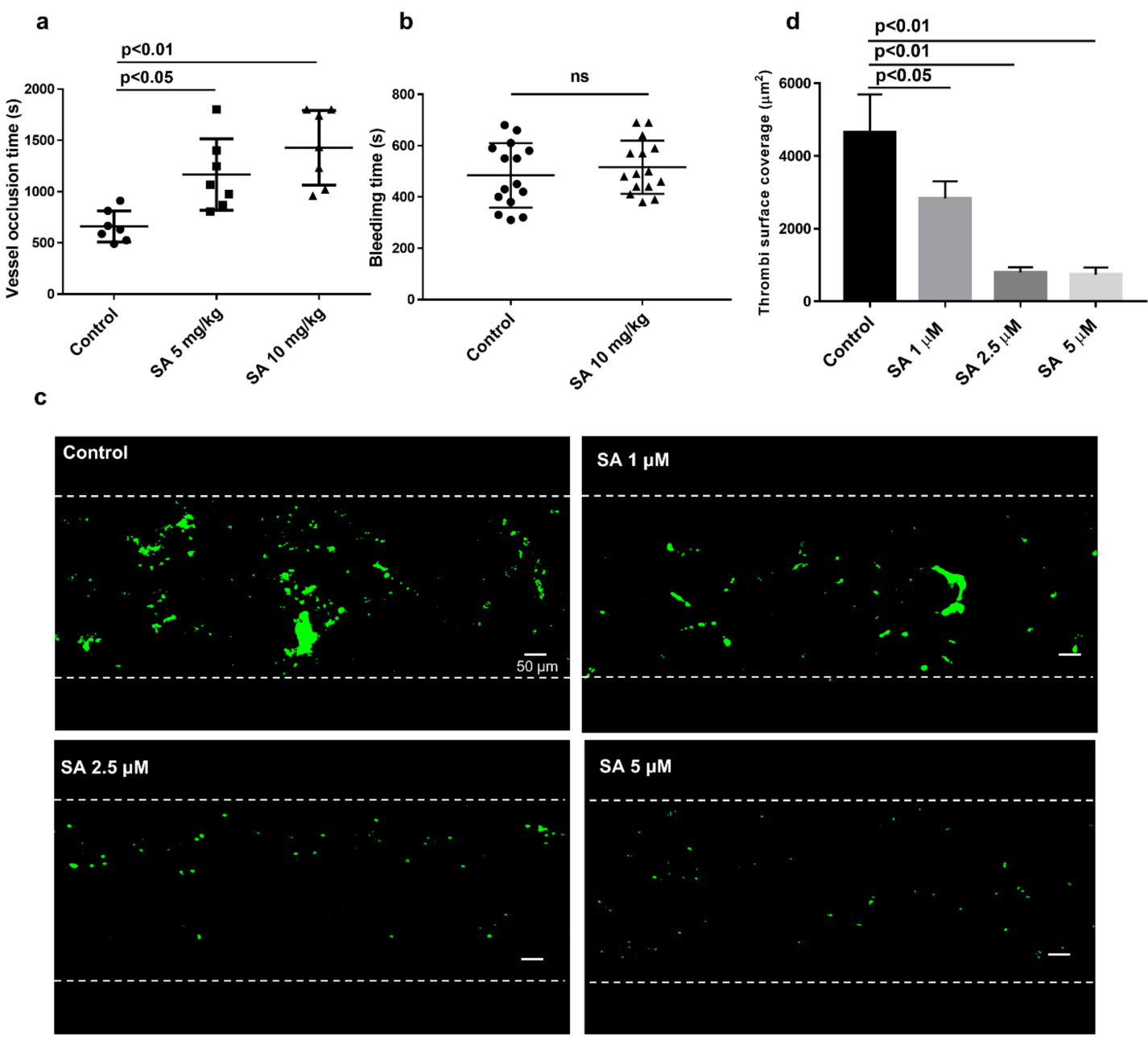

Figure 2. Sanguinarine inhibits the formation of thrombus in vivo and in vitro without prolonging bleeding time. (a) Summary data of ferric chloride $\left(\mathrm{FeCl}_{3}\right)$-induced thrombus formation. Thrombus formation in vivo was assessed by occlusion 
time(s) after $\mathrm{FeCl}_{3}$-induced injury of the carotid artery, which was measured with a doppler flow probe. The occlusion time of the sanguinarine-treated $(5 \mathrm{mg} / \mathrm{kg}$ or $10 \mathrm{mg} / \mathrm{kg}$, i.g.) were compared with the control (saline $+5 \%$ DMSO i.g.) group. The results were expressed as mean $\pm \operatorname{SEM}(n=7)$ and were analyzed using one-way ANOVA. (b) The effect of sanguinarine on bleeding time. Results are shown as mean \pm SEM $(n=15)$, and data were analyzed using an unpaired $t$ test. (c) Sanguinarine reduced thrombosis in vitro. Washed human platelets were labeled with CellTrace Calcein Green and then incubated with DMSO (control) or sanguinarine $(1,2.5$ and $5 \mu \mathrm{M})$ for $10 \mathrm{~min}$. The mixture of labeled platelets and washed red blood cells (with a hematocrit of about $40 \%$ ) and $\mathrm{CaCl}_{2} / \mathrm{MgCl}_{2}(75 \mathrm{mM} / 37.5 \mathrm{mM})$ was perfused through Bioflux plates at a wall shear rate of $2000 \mathrm{~s}^{-1}$ for $5 \mathrm{~min}$. Representative images of surface coverage were revealed. (d) Summary data of area covered by platelets at the 5 min time point were studied and measured (scale bars, $50 \mu \mathrm{M})$. Results and data were collected from at least five separate independent experiments, analyzed using one-way ANOVA analysis and presented as mean $\pm \operatorname{SEM}(n=5)$.

\subsection{Sanguinarine Inhibits Human Platelet Aggregation Induced by Collagen and Collagen-Related Peptide}

As the arterial injury initially exposed the collagen under the endothelium, the current study focused on checking sanguinarine's effect on collagen-induced human platelet aggregation. Platelet aggregation was induced by collagen $(1 \mu \mathrm{g} / \mathrm{mL})$ and CRP $(0.25 \mu \mathrm{g} / \mathrm{mL})$ after different doses of sanguinarine or DMSO (control) pretreated at $37{ }^{\circ} \mathrm{C}$ for $10 \mathrm{~min}$. The results indicated that sanguinarine inhibited platelet aggregation induced by collagen and collagen-related peptide in a dose-dependent manner. The high dose $(5 \mu \mathrm{M})$ sanguinarine almost completely inhibited collagen and collagen-related peptide-induced platelet aggregation (Figure 3b).

a

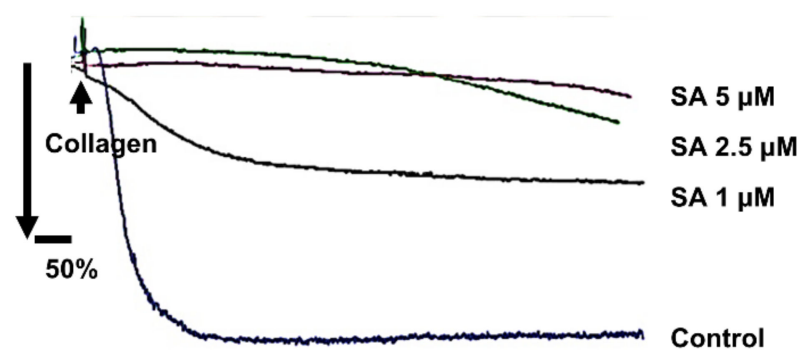

Collagen $1 \mu \mathrm{g} / \mathrm{ml}$

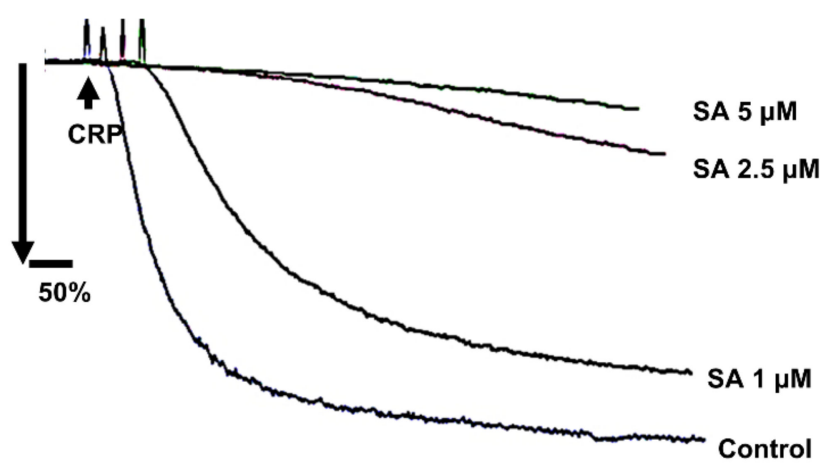

b

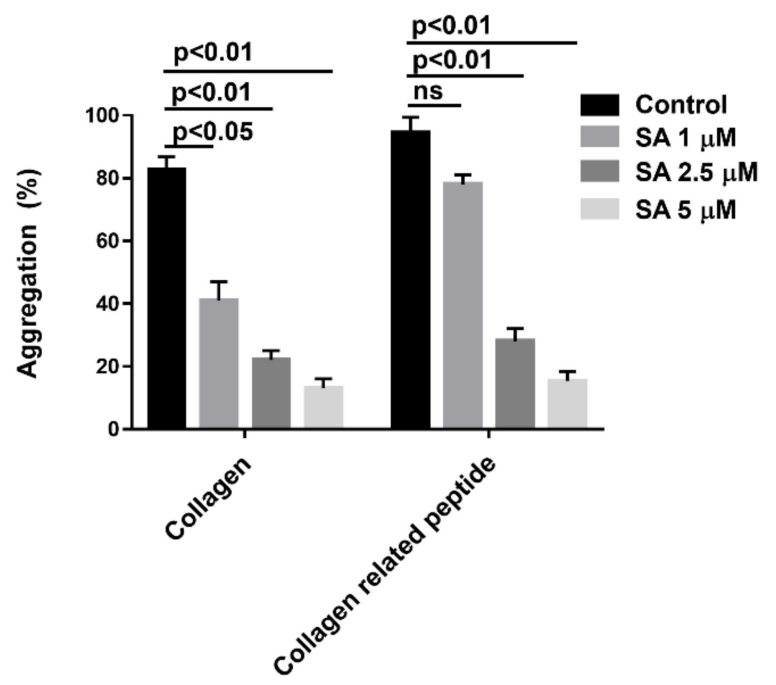

Collagen related peptide $0.25 \mu \mathrm{g} / \mathrm{ml}$

Figure 3. Effects of sanguinarine on collagen and collagen-related peptide-induced human platelet aggregation of washed human platelets. (a) Washed human platelets $\left(3 \times 10^{8} / \mathrm{mL}\right)$ were preincubated for 10 min with different concentrations of sanguinarine $(1,2.5,5 \mu \mathrm{M})$ or DMSO (control), followed by stimulation with different agonists. (b) Data were shown as mean $\pm \operatorname{SEM}(n=5)$ and examined using one-way ANOVA analysis. 


\subsection{Sanguinarine Inhibits Collagen-Induced Human Platelet Granule Secretion and Integrin $\alpha$ Iib $\beta 3$ Activation}

To examine the influence of sanguinarine on platelet granule release, human platelets were initially incubated with various doses of sanguinarine at $37^{\circ} \mathrm{C}$ for $10 \mathrm{~min}$, and then stimulated with collagen. As shown in Figure $4 a, b$, sanguinarine reduced collageninduced platelet ATP release in a dose-dependent manner. A $5 \mu \mathrm{M}$ dose of sanguinarine almost completely inhibited the ATP release. In addition, sanguinarine dose-dependently decreased the P-selectin expression and PAC-1 binding. The P-selectin expression decreased from $74.5 \%$ to $49.23 \%(1 \mu \mathrm{M}), 15.09 \%(2.5 \mu \mathrm{M})$ and $14.58 \%(5 \mu \mathrm{M})$, respectively (Figure $4 \mathrm{c}, \mathrm{d}$ ). The PAC-1 binding in collagen-stimulated platelets dropped from $73.67 \%$ to $40.63 \%(1 \mu \mathrm{M})$, $8.33 \%(2.5 \mu \mathrm{M})$ and $3.9 \%(5 \mu \mathrm{M})$, respectively (Figure $4 \mathrm{e}, \mathrm{f})$. This clearly indicates that sanguinarine had an inhibitory effect on collagen-stimulated P-selectin expression and PAC-1 binding in a dose-dependent manner.

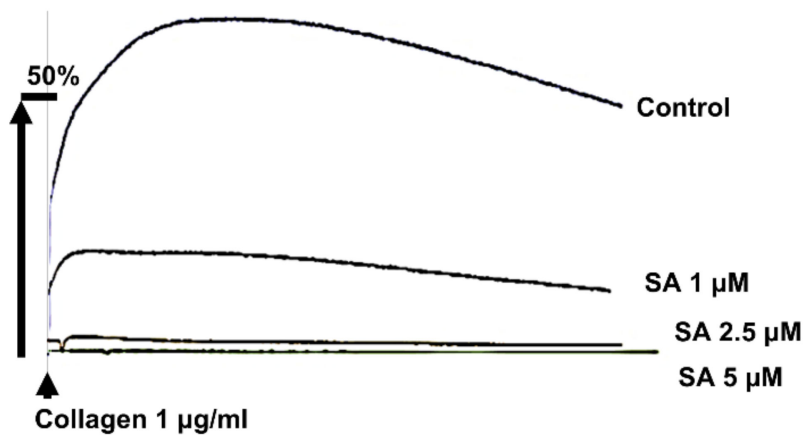

b
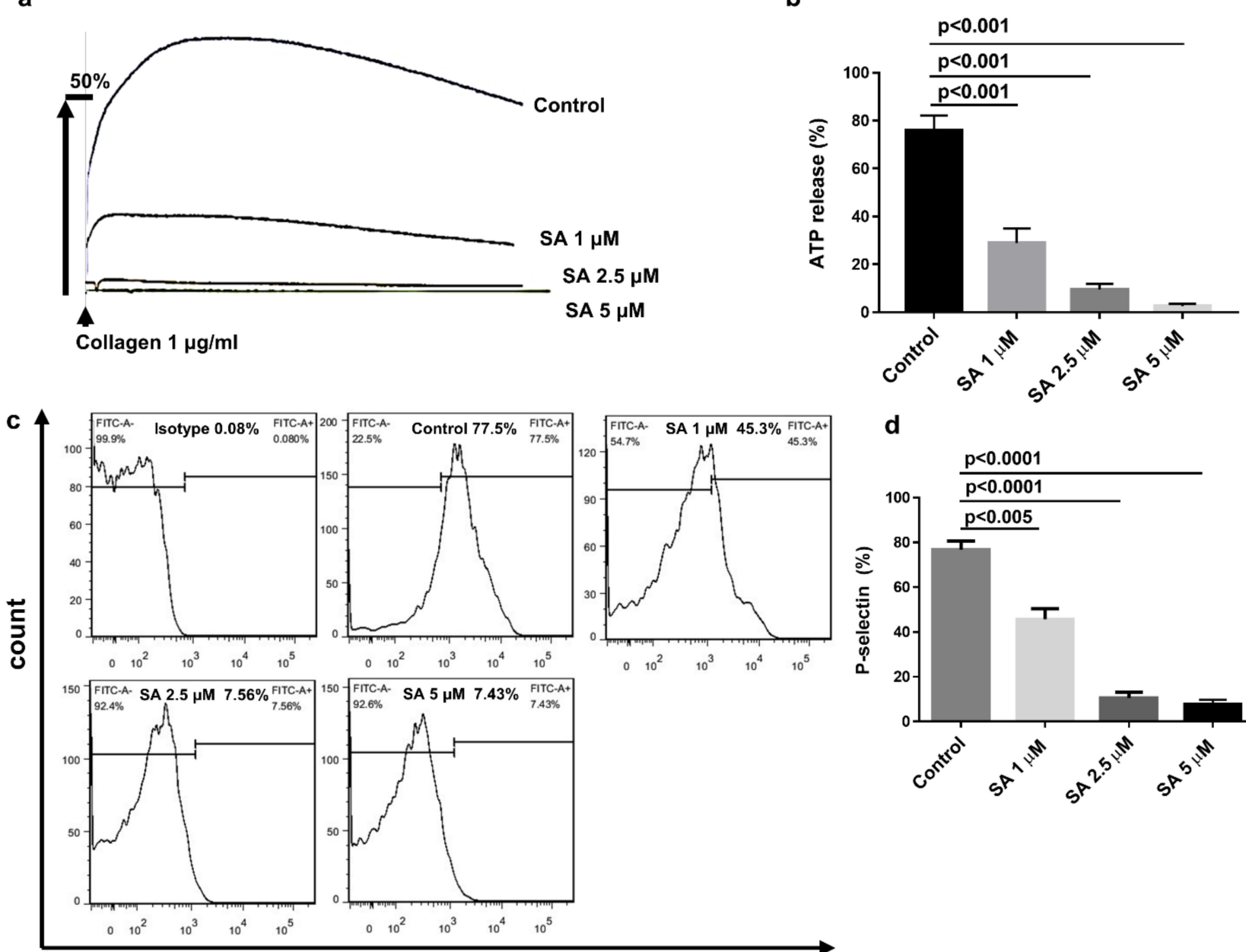

d

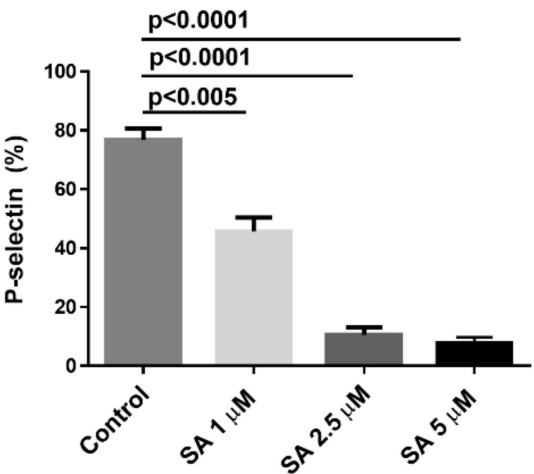

FITC-CD62P

Figure 4. Cont. 

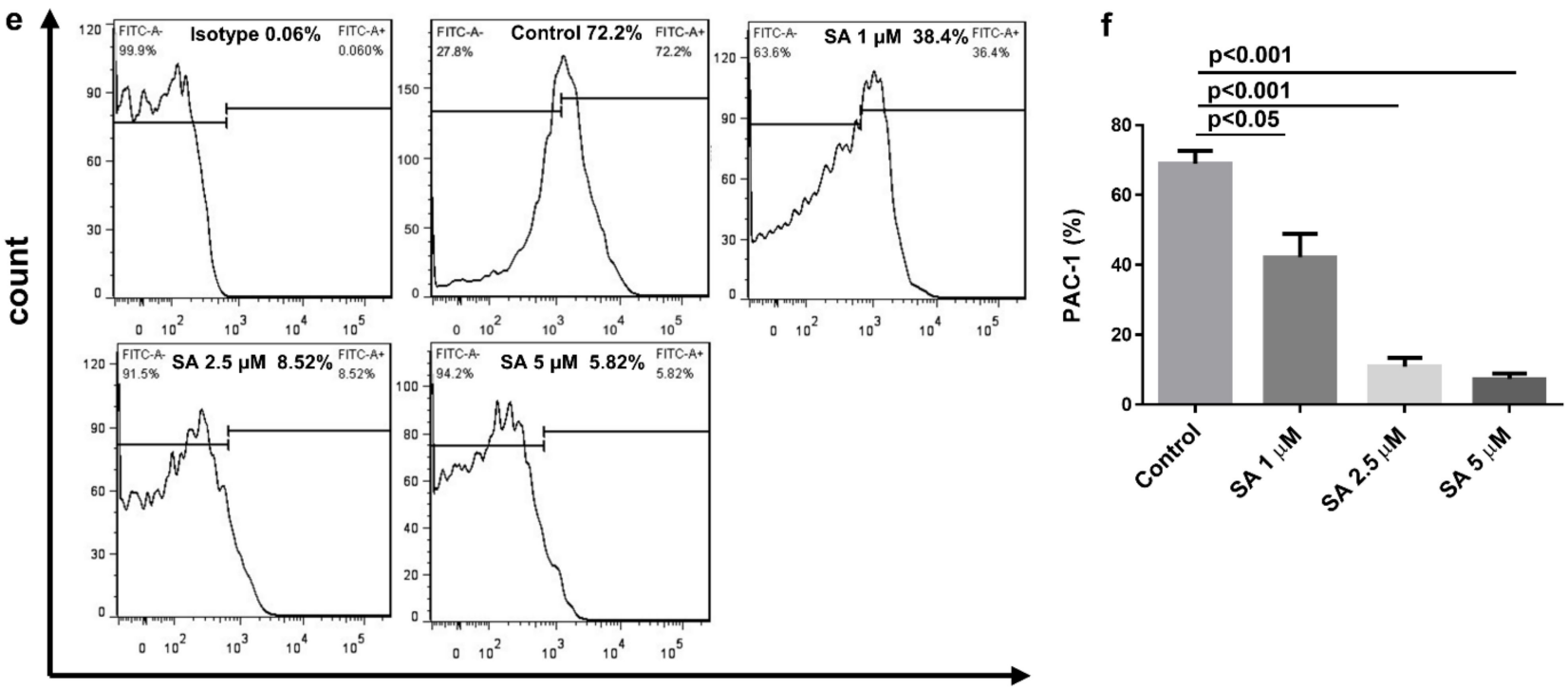

FITC-PAC-1

Figure 4. Sanguinarine decreases collagen-induced human platelet granule release and integrin $\alpha \mathrm{Ilb} \beta 3$ activation. (a) Washed human platelets were prepared as shown in Figure 3. ATP secretion was documented and computed following the instructions in the Materials and Methods Section. (b) Data were shown as mean \pm SEM $(n=5)$ and examined using one-way ANOVA analysis. (c-f) First, washed human platelets $\left(5 \times 10^{7} / \mathrm{mL}\right)$ were preincubated for $10 \mathrm{~min}$ at $37^{\circ} \mathrm{C}$ with sanguinarine $(1,2.5,5 \mu \mathrm{M})$ or DMSO (control) in the presence of FITC-conjugated P-selectin and FITC-conjugated PAC-1 antibodies. Afterward, the platelets were stimulated with collagen $(2 \mu \mathrm{g} / \mathrm{mL})$ and incubated for another $5 \mathrm{~min}$. P-selectin expression $(\mathbf{c}, \mathbf{d})$ and PAC-1 binding $(\mathbf{e}, \mathbf{f})$ were identified by flow cytometry. Results and data were expressed as mean $\pm \operatorname{SEM}(n=5)$.

\subsection{Sanguinarine Inhibits Collagen-Induced Human Platelet Intracellular Signal Transduction}

To further investigate the specific molecular mechanism of sanguinarine in inhibiting collagen-induced human platelet activation, we checked the phosphorylation of several proteins downstream of the GPVI signaling pathway, such as Syk-PLC $\gamma 2$ and PI3K-AktGSK3 $\beta$. The results (Figure $5 \mathrm{a}, \mathrm{b}$ ) showed that $1 \mu \mathrm{M}, 2.5 \mu \mathrm{M}$ and $5 \mu \mathrm{M}$ of sanguinarine significantly inhibited Syk phosphorylation, while only $5 \mu \mathrm{M}$ of sanguinarine appeared to inhibit PLC $\gamma 2$ phosphorylation. The PI3K-Akt-GSK3 $\beta$ pathway plays a key role in activating platelets, and is an important component downstream of GPVI signaling $[23,24]$. As shown in Figure 5c,d, sanguinarine effectively inhibited the phosphorylation of PI3K, Akt and GSK3 $\beta$ in collagen-stimulated platelets. The results suggested that sanguinarine negatively regulated the phosphorylation of Syk-PLC $\gamma 2$ and PI3K-Akt-GSK3 $\beta$ downstream of platelet GPVI.

a

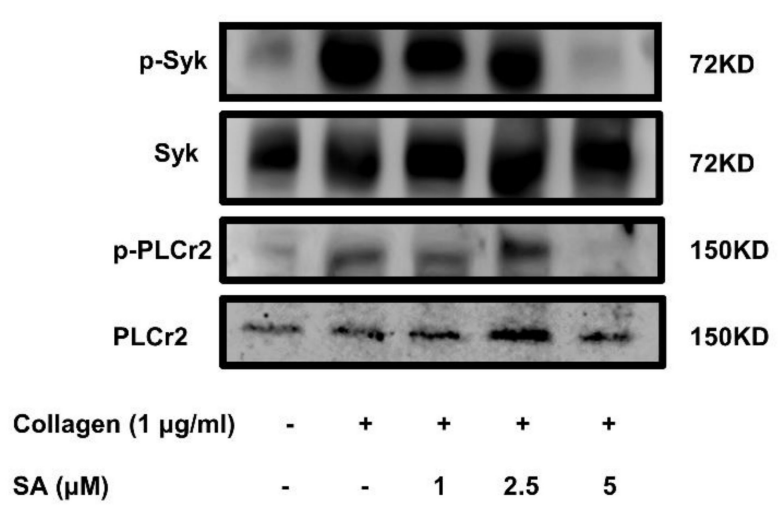

b

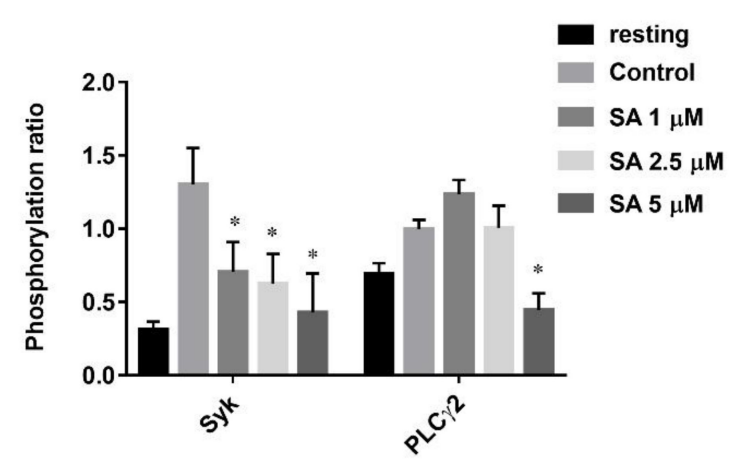

Figure 5. Cont. 
C

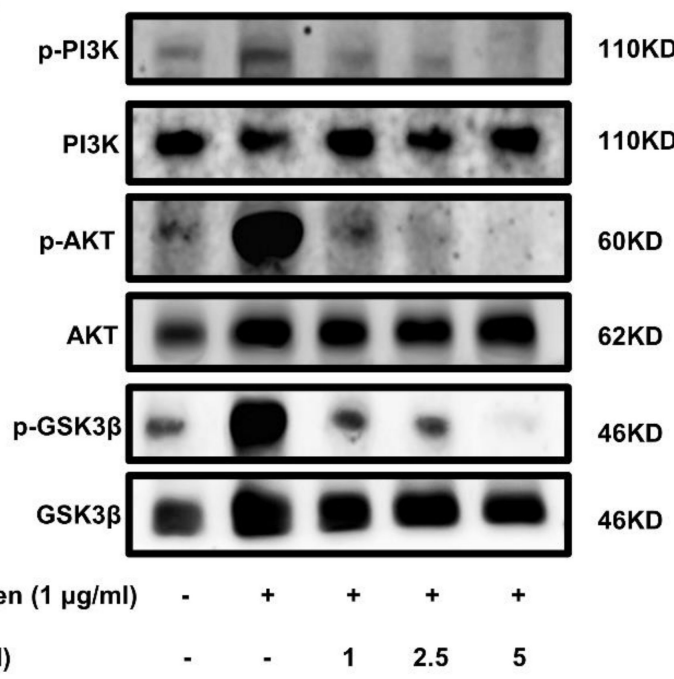

d

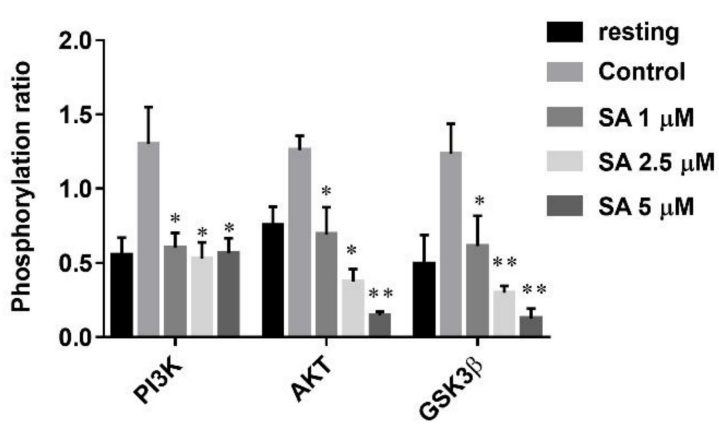

Figure 5. Sanguinarine has an inhibitory effect on collagen-induced phosphorylation of the signaling cascade. (a,c) Washed human platelets were treated initially with sanguinarine $\left(1,2.5,5 \mu \mathrm{M}\right.$ ) or DMSO (control) at $37{ }^{\circ} \mathrm{C}$ for 10 min, then stimulated with collagen $(1 \mu \mathrm{g} / \mathrm{mL})$ for $5 \mathrm{~min}$, and later underwent lysis with lysis buffer, followed by Western blotting using specific antibodies. (b,d) The Syk/PLC $\gamma 2$ and PI3K/Akt/GSK3 $\beta$ phosphorylation ratios were measured. The blot was a representative of three independent experiments that showed statistical significance at ${ }^{*}<0.05$ and ${ }^{* *} p<0.01$ compared with the control group $(n=5)$.

\subsection{Sanguinarine Reduces Platelet Intracellular $\mathrm{Ca}^{2+}$ Concentrations $\left(\left[\mathrm{Ca}{ }^{2+}\right]\right.$ i) in a Dose-Dependent Manner}

During the process of platelet activation, intracellular calcium signal plays a very important role [22]. Most of the agonists cause an increase of intracellular calcium concentration after platelet activation [25]. Flou-3AM was used in combination with intracellular free calcium ions to detect the fluorescence intensity by flow cytometry. The extracellular free calcium was complexed with EDTA, and then the extracellular $2 \mathrm{mM}$ calcium and collagen $(2 \mu \mathrm{g} / \mathrm{mL})$ were added to detect the intracellular $\mathrm{Ca}^{2+}$ mobilization in platelets. As shown in Figure 6a,b, sanguinarine inhibited the increases in $\left[\mathrm{Ca}^{2+}\right]$ i caused by collagen in a dose-dependent manner, and $5 \mu \mathrm{M}$ of sanguinarine almost blocked calcium mobilization.

a

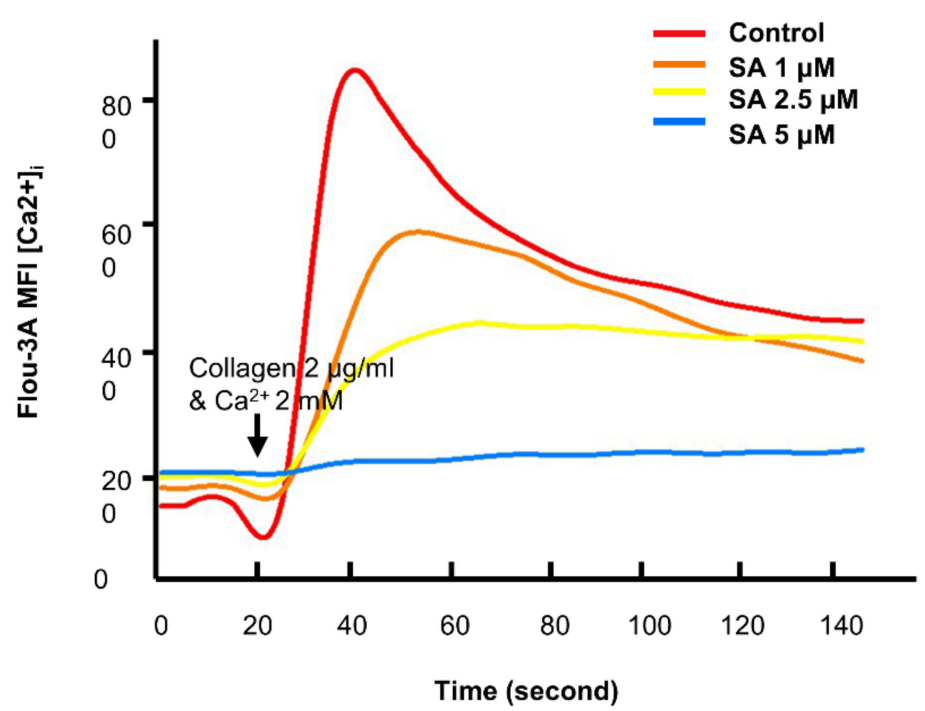

b

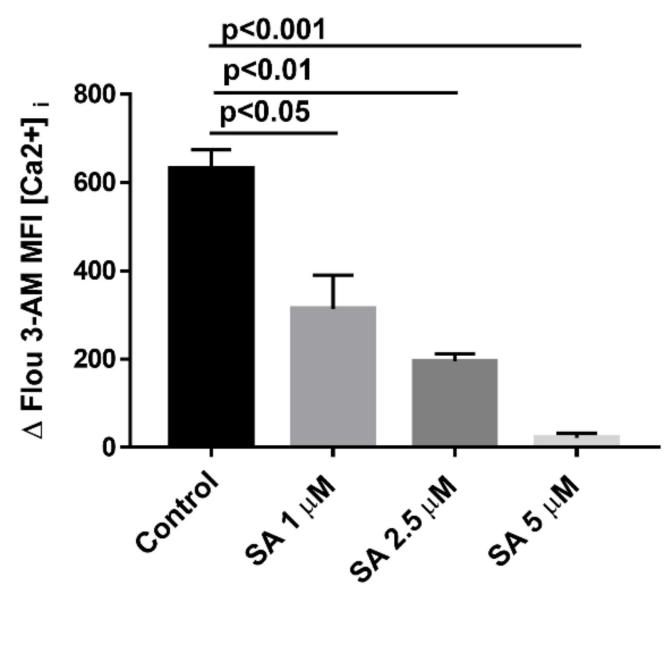

Figure 6. Sanguinarine dose-dependently attenuates intracellular $\mathrm{Ca}^{2+}$ concentration $\left(\left[\mathrm{Ca}^{2+}\right] \mathrm{i}\right)$ in human platelets. (a) Intracellular $\mathrm{Ca}^{2+}$ flux was measured by flow cytometry. Washed human platelets $\left(5 \times 10^{7} / \mathrm{mL}\right)$ were labeled with $1 \mu \mathrm{M}$ 
Fluo-3AM at $37{ }^{\circ} \mathrm{C}$ for $30 \mathrm{~min}$, then incubated with sanguinarine (1, 2.5 and $5 \mu \mathrm{M}$ ) or DMSO (control) for $10 \mathrm{~min}$. After collecting a baseline for $20 \mathrm{~s}$, collagen $(2 \mu \mathrm{g} / \mathrm{mL})$ and $2 \mathrm{mM}$ extracellular calcium were added to the FACS tube, and the change in fluorescence intensity was recorded on BD Biosciences flow cytometer and analyzed using Flowjo software. The fitting curve was plotted using Sigma Plot software. (b) Values of $\left[\mathrm{Ca}^{2+}\right]$ i elevation upon collagen stimulation shown in (a) were plotted as mean \pm SEM from five independent experiments.

\subsection{Sanguinarine Negatively Regulates the Integrin $\alpha I I b \beta 3$ "Outside-In" Signaling}

We also found that sanguinarine inhibited human platelet adhesion and spreading on the fibrinogen-coated matrix (Figure 7a,b). Compared with the control group, sanguinarine inhibited platelet spreading on immobilized fibrinogen. The platelet surface coverage was much smaller at $5 \mu \mathrm{M}$. We further analyzed the molecular mechanism of sanguinarine on platelet outside-in signal transduction by detecting the related protein's phosphorylationinspreading platelet. $\beta 3$ phosphorylation is a direct indicator of $\alpha \operatorname{Ilb} \beta 3$ activation, and Src activation is also associated with outside-in signal transduction [26]. The results demonstrated that phosphorylation of $\beta 3$ and Src (Tyr 416) was reduced significantly in the presence of sanguinarine (Figure $7 \mathrm{c}, \mathrm{d}$ ). This suggests that sanguinarine plays a significant role in inhibiting the $\alpha \mathrm{IIb} \beta 3$ outside-in signal transduction.

a
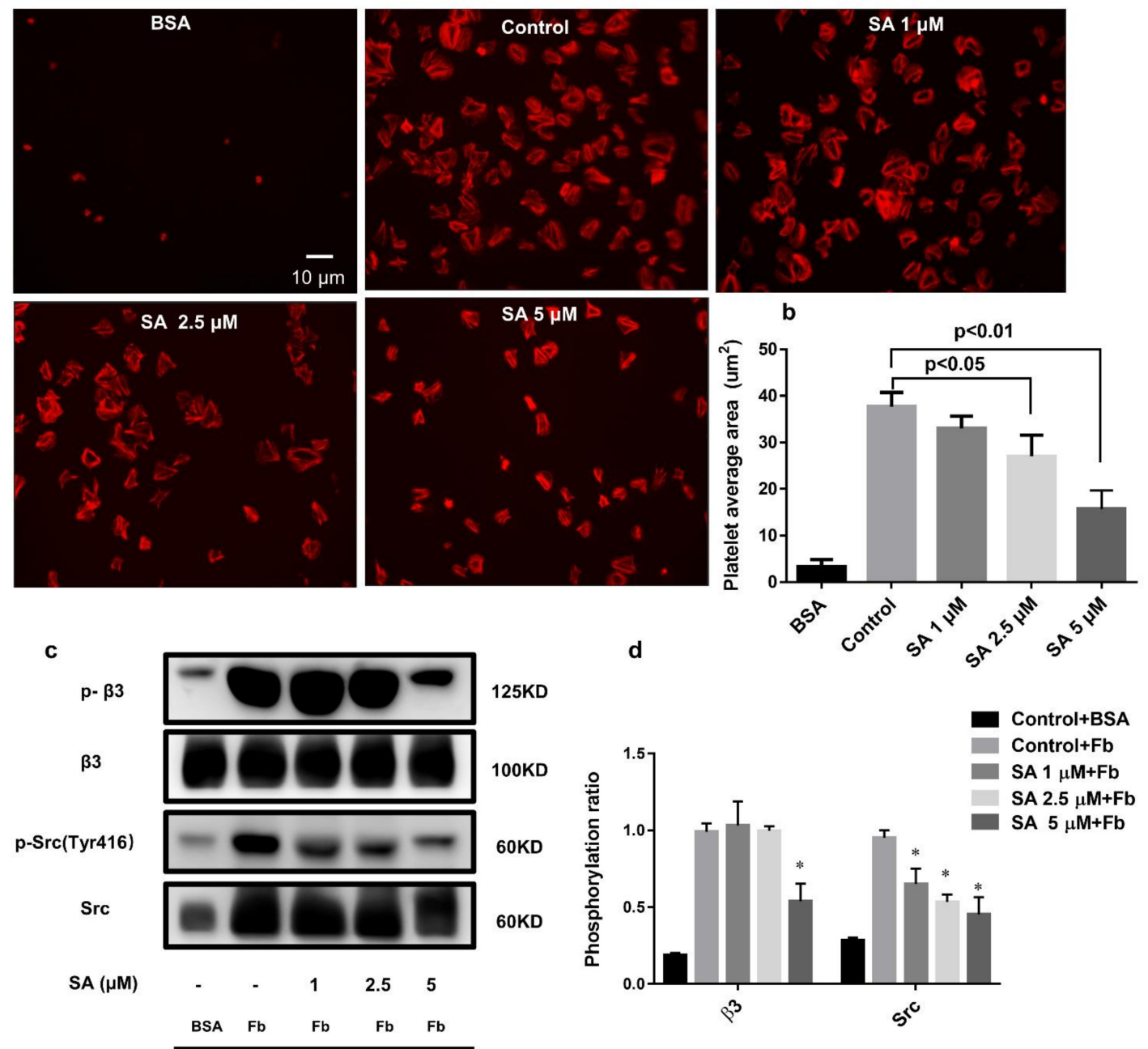

d

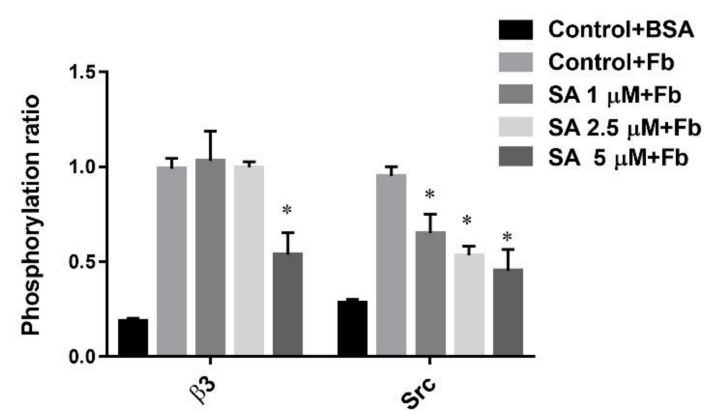

Immobilized protein

Figure 7. Sanguinarine dose-dependently represses human platelet spreading on the fibrinogen-coated surface and inhibits integrin $\alpha \mathrm{Ilb} \beta 3$-mediated outside-in signaling. (a) A representative image of platelets spreading on the coated BSA or fibrinogen cover glasses. (b) The figure expressed the quantity of the single adherent platelet area as shown in the right panel, 
and the average coverage of the spreading platelets in five independent experiments. (c,d) Typical figure of phosphorylation of $\beta 3 /$ Src of lysed spreading platelets for five independent experiments. The data had statistical significance at $p<0.05$ when compared to the control group.

\section{Discussion}

The effects of sanguinarine on arterial thrombosis in vivo and in vitro were investigated in this study. Sanguinarine dose-dependently inhibited human platelet aggregation, $\alpha$-granule and dense granule release, $\alpha \mathrm{Ilb} \beta 3$ activation and intracellular calcium mobilization induced by collagen. It also inhibited platelet spreading on immobilized fibrinogen. This suggests that sanguinarine inhibits collagen-induced platelet activation as well as integrin $\alpha \mathrm{Ilb} \beta 3$ “outside-in" signal transduction. From the molecular mechanism, it was clear that sanguinarine inhibited the phosphorylation of downstream signal molecules of the collagen specific receptor GPVI signal pathway, including Syk-PLC $\gamma 2$ and PI3K-Akt-GSK3 $\beta$. Moreover, it also inhibited $\alpha \mathrm{Ilb} \beta 3$-mediated $\beta 3$-Src signaling (Figure 8 ). Sanguinarine inhibited artery thrombosis induced by $\mathrm{FeCl}_{3}$ in mice, but had no influence on tail bleeding time. This suggests that it had no obvious risk of bleeding.

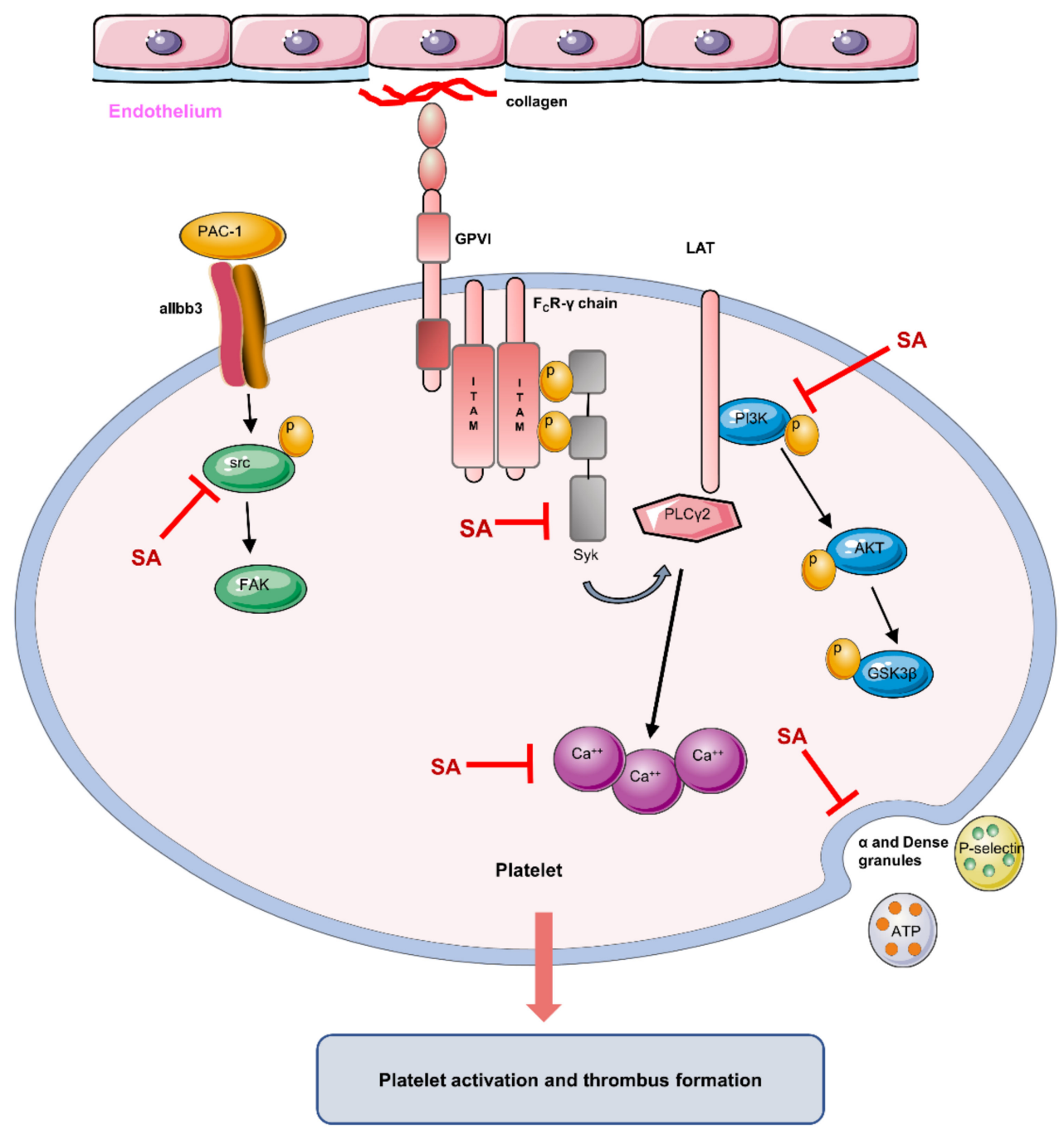

Figure 8. Schematic of sanguinarine antiplatelet activity. Sanguinarine attenuates collagen-induced platelet activation (including $\alpha$ and dense granule release) and thrombus formation by targeting the GPVI pathway (inhibiting the phosphorylation of Syk-PLC $\gamma 2$ and PI3K-Akt-GSK3 $\beta$ ), intracellular $\mathrm{Ca}^{2+}$ mobilization and integrin $\alpha \operatorname{IIb} \beta 3$-mediated "outside-in" signal transduction (inhibiting the phosphorylation of src). (Inhibit $-\mathbf{I}$; Induce $\longrightarrow$ ) 
Platelet adhesion and aggregation is crucial in the process of arterial thrombosis [1,27]. A recognized arterial thrombosis model is $\mathrm{FeCl}_{3}$-induced carotid artery thrombosis, in which multiple anticoagulants and antiplatelet drugs are sensitive to [28]. Therefore, sanguinarine has well-established antithrombotic properties in mice by prolonging the closure time of blood vessels while not increasing the tail bleeding time (Figure $2 a, b$ ). In vivo, the shear force exerted by blood laminar flow is considered an important environmental factor in the process of platelet activation under normal and pathological conditions [2]. It was reported that the shear rates of $1002.6 \mathrm{~s}^{-1}, 2282.67 \mathrm{~s}^{-1}$ and $3989.248 \mathrm{~s}^{-1}$ represent shear conditions in normal arteries, moderately stenotic arteries and severely stenotic arteries, respectively [21]. To check sanguinarine antiarterial thrombosis in vitro, we used Bioflux $1000 \mathrm{Z}$ to analysis human blood thrombus formation in high shear force $\left(2000 \mathrm{~s}^{-1}\right)$ simulating arterial stenosis. The results presented that sanguinarine significantly reduced the adhesion area (Figure 2c,d) of platelets in flow, which suggested the possibility of antithrombosis in clinic.

In Jeng's study [14], the concentration of collagen used in platelet aggregation was $10 \mu \mathrm{g} / \mathrm{mL}$, which was much higher than that in physiological and pathological conditions. In our study, we used $1 \mu \mathrm{g} / \mathrm{mL}$ collagen and $0.25 \mu \mathrm{g} / \mathrm{mL}$ collagen-related peptide to activate platelets. As shown in Figure $3 \mathrm{a}, \mathrm{b}$, sanguinarine revealed significant antiaggregation in a dose-dependent manner. Three types of platelet secretory granules ( $\alpha$ granules, dense granules and lysozyme) release different contents when platelets are activated to participate in various pathophysiological processes such as hemostasis, thrombosis and immune reaction [29]. Platelet $\alpha$ granules are rich in P-selectin, fibrinogen and $\mathrm{vWF}$, and detection of the expression of P-selectin on the membrane reflects $\alpha$ granule release during platelet activation. While dense granules contain ADP, ATP and 5-HT, detection of ATP reflects dense granule release [30]. As shown in Figure 4, sanguinarine significantly inhibited ATP release and the expression of P-selectin, which suggests that sanguinarine inhibits both $\alpha$ granule and dense granule release. In addition to P-selectin expression, the direct binding of monoclonal antibody PAC-1 is considered to be another key marker of platelet activation [31]. Sanguinarine decreased collagen-induced platelet $\alpha \mathrm{IIb} \beta 3$ activation in a dose-dependent manner, which further confirmed its inhibitory effect on platelet "inside-out" signal transduction (Figure 4e,f).

Collagen activates signal transduction based on Src family kinase (SFK) by binding to GPVI receptors, resulting in activation of Syk/PLC $\gamma 2 /$ PKC [32,33]. Through the analysis of precipitates after collagen-induced platelet aggregation, it was likely that sanguinarine reduced the Syk phosphorylation more than that of PLC $\gamma 2$. PI3K is an earlier-reported signal subunit $[34,35]$ that is also activated by collagen-GPVI mediated PLC $\gamma 2$. A serine/threonine kinase, AKT, which is the main downstream effector of PI3K, is attracted to the platelet plasma membrane through its PIP3 binding domain and then phosphorylated by PDK1 and mTORC2 [23]. The study conducted by Barry [3] has shown that AKT has an important role in collage-induced platelet activation via the GPVI receptor. In addition, the role of GSK3 $\beta$ in platelet function was also proved by inhibitors and genetic experiments [24]. Our results confirmed that sanguinarine also acted as a repressor of PI3K-Akt-GSK3 $\beta$ signaling to weaken collagen-stimulated platelet activation.

The increase of intracellular $\mathrm{Ca}^{2+}$ in platelets is a key signal event that is essential for most of the major functional responses in the process of platelet activation, including cytoskeleton rearrangement, particle release and integrin $\alpha \operatorname{Ilb} \beta 3$ inside-out signaling [22,36]. A study by Rink et al. confirmed that in the process of activating platelets, various agonists, such as collagen, TxA2, ADP and thrombin, lead to an increase concentration of intracellular $\mathrm{Ca}^{2+}$, although they have an effect on different platelet receptors and activate different signal pathways [25]. The key second messenger downstream of most platelet signaling pathways is $\mathrm{Ca}^{2+}$, so the regulation of $\mathrm{Ca}^{2+}$ signal could be an interesting target for platelet inhibition [37]. Our study indicated that sanguinarine greatly inhibited the increase of $\left[\mathrm{Ca}^{2+}\right] \mathrm{i}$ in platelets induced by collagen, and the dose-dependent trend was consistent with its antiplatelet aggregation effect (Figure 6a,b). 
Fibrinogen plays a crucial role in cytoskeleton reorganization and platelet spreading after stabilizing thrombosis and growth by binding to the activated integrin $\alpha \mathrm{IIb} \beta 3$ and triggering the "outside-in" signal $[26,38]$. At the beginning of the outside-in signal, integrin $\alpha \operatorname{Ilb} \beta 3$ subunit $\beta 3$ can be phosphorylated, resulting the phosphorylation of Src (Tyr416), which then causes the phosphorylation of other downstream proteins [39]. Our study confirmed that sanguinarine inhibited the phosphorylation of $\beta 3$ and Src in spreading platelets on fibrinogen, which indicated that it had a significant inhibitory effect on $\alpha \mathrm{IIb} \beta 3$ mediated outside-in signaling.

However, both previous studies [14] and our results have confirmed that sanguinarine can also inhibit thrombin-induced platelet aggregation (data not shown). Whether sanguinarine inhibits the platelet function by negatively regulating thrombin receptor-linked signaling pathways will be confirmed in future experiments.

\section{Conclusions}

Our study indicated that sanguinarine inhibited arterial thrombosis in a dose-dependent manner. Additionally, sanguinarine inhibited platelet aggregation, granule release and spreading. The underlying mechanisms are as follows (Figure 8): 1. Inhibiting the downstream signal molecules of the collagen-specific GPVI receptor signal pathway, including the phosphorylation of Syk-PLC $\gamma 2$ and PI3K-Akt-GSK3 $\beta ; 2$. Inhibiting collagen-induced intracellular calcium mobilization; 3 . Negatively regulating the $\alpha \operatorname{Ilb} \beta 3$ "outside-in" signal transduction. The study suggests that sanguinarine may be a potential candidate for the treatment of thrombotic disease.

Author Contributions: Conceptualization, Z.-Y.M. and D.S.; methodology, D.S. and Y.Z.; software, M.L. and X.-B.Z.; validation, D.S. and Y.Z.; formal analysis, Y.L.; investigation, J.-B.C. and D.-S.Y.; resources, Z.-Y.M.; data curation, D.S.; writing—original draft preparation, D.S.; writing-review and editing, D.S. and Z.-Y.M.; visualization, Y.Z.; supervision, R.M.; project administration, Z.-Y.M.; funding acquisition, Z.-Y.M. and A.-D.H. All authors have read and agreed to the published version of the manuscript.

Funding: This research was funded by The National Natural Science Foundation of China (No. 81970129 to Z.-Y.M.; No.81800133 to A.-D.H.) and Foundation of Ministry of Education of China (No. 6141A02022633 to Z.-Y.M.).

Institutional Review Board Statement: The study was conducted according to the guidelines of the Declaration of Helsinki, and approved by the Ethics Committee of Tongii Medical College of Huazhong University of Science and Technology.

Informed Consent Statement: Informed consent was obtained from all subjects involved in the study.

Conflicts of Interest: The authors declare no conflict of interest.

\section{References}

1. Van der Meijden, P.E.J.; Heemskerk, J.W.M. Platelet biology and functions: New concepts and clinical perspectives. Nat. Rev. Cardiol. 2019, 16, 166-179. [CrossRef]

2. Cosemans, J.M.; Angelillo-Scherrer, A.; Mattheij, N.J.; Heemskerk, J.W. The effects of arterial flow on platelet activation, thrombus growth, and stabilization. Cardiovasc. Res. 2013, 99, 342-352. [CrossRef]

3. Barry, F.A.; Gibbins, J.M. Protein kinase B is regulated in platelets by the collagen receptor glycoprotein VI. J. Biol. Chem. 2002, 277, 12874-12878. [CrossRef]

4. Liang, M.L.; Da, X.W.; He, A.D.; Yao, G.Q.; Xie, W.; Liu, G.; Xiang, J.Z.; Ming, Z.Y. Pentamethylquercetin (PMQ) reduces thrombus formation by inhibiting platelet function. Sci. Rep. 2015, 5, 11142. [CrossRef] [PubMed]

5. Liu, G.; Xie, W.; He, A.D.; Da, X.W.; Liang, M.L.; Yao, G.Q.; Xiang, J.Z.; Gao, C.J.; Ming, Z.Y. Antiplatelet activity of chrysin via inhibiting platelet alphaIIbbeta3-mediated signaling pathway. Mol. Nutr. Food Res. 2016, 60, 1984-1993. [CrossRef] [PubMed]

6. Authi, K.S. Orai1: A channel to safer antithrombotic therapy. Blood 2009, 113, 1872-1873. [CrossRef] [PubMed]

7. Konopatskaya, O.; Matthews, S.A.; Harper, M.T.; Gilio, K.; Cosemans, J.M.; Williams, C.M.; Navarro, M.N.; Carter, D.A.; Heemskerk, J.W.; Leitges, M.; et al. Protein kinase C mediates platelet secretion and thrombus formation through protein kinase D2. Blood 2011, 118, 416-424. [CrossRef] [PubMed]

8. Michelson, A.D. Antiplatelet therapies for the treatment of cardiovascular disease. Nat. Rev. Drug Discov. 2010, 9, 154-169. [CrossRef] 
9. Stolla, M.; Stefanini, L.; Roden, R.C.; Chavez, M.; Hirsch, J.; Greene, T.; Ouellette, T.D.; Maloney, S.F.; Diamond, S.L.; Poncz, M.; et al. The kinetics of alphaIlbbeta3 activation determines the size and stability of thrombi in mice: Implications for antiplatelet therapy. Blood 2011, 117, 1005-1013. [CrossRef]

10. Shaito, A.; Thuan, D.T.B.; Phu, H.T.; Nguyen, T.H.D.; Hasan, H.; Halabi, S.; Abdelhady, S.; Nasrallah, G.K.; Eid, A.H.; Pintus, G. Herbal Medicine for Cardiovascular Diseases: Efficacy, Mechanisms, and Safety. Front. Pharmacol. 2020, 11, 422. [CrossRef]

11. Mackraj, I.; Govender, T.; Gathiram, P. Sanguinarine. Cardiovasc. Ther. 2008, 26, 75-83. [CrossRef]

12. Grenby, T.H. The use of sanguinarine in mouthwashes and toothpaste compared with some other antimicrobial agents. Br. Dent. J. 1995, 178, 254-258. [CrossRef]

13. Basu, P.; Kumar, G.S. Sanguinarine and Its Role in Chronic Diseases. Adv. Exp. Med. Biol. 2016, 928, 155-172. [CrossRef]

14. Jeng, J.H.; Wu, H.L.; Lin, B.R.; Lan, W.H.; Chang, H.H.; Ho, Y.S.; Lee, P.H.; Wang, Y.J.; Wang, J.S.; Chen, Y.J.; et al. Antiplatelet effect of sanguinarine is correlated to calcium mobilization, thromboxane and cAMP production. Atherosclerosis 2007, 191, 250-258. [CrossRef] [PubMed]

15. Day, S.M.; Reeve, J.L.; Myers, D.D.; Fay, W.P. Murine thrombosis models. Thromb. Haemost. 2004, 92, 486-494. [CrossRef] [PubMed]

16. Li, W.; Nieman, M.; Sen Gupta, A. Ferric Chloride-induced Murine Thrombosis Models. J. Vis. Exp. 2016. [CrossRef] [PubMed]

17. Tyagi, T.; Ahmad, S.; Gupta, N.; Sahu, A.; Ahmad, Y.; Nair, V.; Chatterjee, T.; Bajaj, N.; Sengupta, S.; Ganju, L.; et al. Altered expression of platelet proteins and calpain activity mediate hypoxia-induced prothrombotic phenotype. Blood 2014, 123, 1250-1260 [CrossRef] [PubMed]

18. Zhou, Y.J.; Xiang, J.Z.; Yuan, H.; Liu, H.; Tang, Q.; Hao, H.Z.; Yin, Z.; Wang, J.; Ming, Z.Y. Neferine exerts its antithrombotic effect by inhibiting platelet aggregation and promoting dissociation of platelet aggregates. Thromb. Res. 2013, 132, 202-210. [CrossRef] [PubMed]

19. Cao, A.; Alluqmani, N.; Buhari, F.H.M.; Wasim, L.; Smith, L.K.; Quaile, A.T.; Shannon, M.; Hakim, Z.; Furmli, H.; Owen, D.M.; et al. Galectin-9 binds IgM-BCR to regulate B cell signaling. Nat. Commun. 2018, 9, 3288. [CrossRef]

20. Xiang, K.; Liu, G.; Zhou, Y.J.; Hao, H.Z.; Yin, Z.; He, A.D.; Da, X.W.; Xiang, J.Z.; Wang, J.L.; Ming, Z.Y. 2,3,5,4'-tetrahydroxystilbene2-O- $\beta$-D-glucoside (THSG) attenuates human platelet aggregation, secretion and spreading in vitro. Thromb. Res. 2014, 133, 211-217. [CrossRef]

21. Singh, N.; Sharma, B. Toxicological Effects of Berberine and Sanguinarine. Front. Mol. Biosci. 2018, 5, 21. [CrossRef]

22. Ilkan, Z.; Wright, J.R.; Goodall, A.H.; Gibbins, J.M.; Jones, C.I.; Mahaut-Smith, M.P. Evidence for shear-mediated Ca ${ }^{2+}$ entry through mechanosensitive cation channels in human platelets and a megakaryocytic cell line. J. Biol. Chem. 2017, 292, 9204-9217. [CrossRef] [PubMed]

23. Guidetti, G.F.; Canobbio, I.; Torti, M. PI3K/Akt in platelet integrin signaling and implications in thrombosis. Adv. Biol. Regul. 2015, 59, 36-52. [CrossRef]

24. Li, D.; August, S.; Woulfe, D.S. GSK3beta is a negative regulator of platelet function and thrombosis. Blood 2008, 111, 3522-3530. [CrossRef] [PubMed]

25. Rink, T.J.; Sage, S.O. Calcium signaling in human platelets. Annu. Rev. Physiol. 1990, 52, 431-449. [CrossRef] [PubMed]

26. Ginsberg, M.H. Integrin activation. BMB Rep. 2014, 47, 655-659. [CrossRef] [PubMed]

27. Koupenova, M.; Kehrel, B.E.; Corkrey, H.A.; Freedman, J.E. Thrombosis and platelets: An update. Eur. Heart J. 2017, 38, 785-791. [CrossRef]

28. Eckly, A.; Hechler, B.; Freund, M.; Zerr, M.; Cazenave, J.P.; Lanza, F.; Mangin, P.H.; Gachet, C. Mechanisms underlying FeCl3-induced arterial thrombosis. J. Thromb. Haemost. 2011, 9, 779-789. [CrossRef] [PubMed]

29. Eckly, A.; Rinckel, J.Y.; Proamer, F.; Ulas, N.; Joshi, S.; Whiteheart, S.W.; Gachet, C. Respective contributions of single and compound granule fusion to secretion by activated platelets. Blood 2016, 128, 2538-2549. [CrossRef]

30. Heijnen, H.; van der Sluijs, P. Platelet secretory behaviour: As diverse as the granules ... or not? J. Thromb. Haemost. 2015, 13, 2141-2151. [CrossRef]

31. Chen, Y.; Ju, L.A.; Zhou, F.; Liao, J.; Xue, L.; Su, Q.P.; Jin, D.; Yuan, Y.; Lu, H.; Jackson, S.P.; et al. An integrin $\alpha_{I I b} \beta_{3}$ intermediate affinity state mediates biomechanical platelet aggregation. Nat. Mater. 2019, 18, 760-769. [CrossRef] [PubMed]

32. Watson, S.P.; Auger, J.M.; McCarty, O.J.; Pearce, A.C. GPVI and integrin alphaIlb beta3 signaling in platelets. J. Thromb. Haemost. 2005, 3, 1752-1762. [CrossRef]

33. Watson, S.P.; Herbert, J.M.J.; Pollitt, A.Y. GPVI and CLEC-2 in hemostasis and vascular integrity. J. Thromb. Haemost. 2010, 8 , 1457-1467. [CrossRef]

34. Gratacap, M.P.; Payrastre, B.; Viala, C.; Mauco, G.; Plantavid, M.; Chap, H. Phosphatidylinositol 3,4,5-trisphosphate-dependent stimulation of phospholipase C-gamma2 is an early key event in FcgammaRIIA-mediated activation of human platelets. J. Biol. Chem. 1998, 273, 24314-24321. [CrossRef]

35. Pasquet, J.M.; Bobe, R.; Gross, B.; Gratacap, M.P.; Tomlinson, M.G.; Payrastre, B.; Watson, S.P. A collagen-related peptide regulates phospholipase Cgamma2 via phosphatidylinositol 3-kinase in human platelets. Biochem. J. 1999, 342 Pt 1, 171-177. [CrossRef]

36. Volz, J.; Kusch, C.; Beck, S.; Popp, M.; Vogtle, T.; Meub, M.; Scheller, I.; Heil, H.S.; Preu, J.; Schuhmann, M.K.; et al. BIN2 orchestrates platelet calcium signaling in thrombosis and thrombo-inflammation. J. Clin. Investig. 2020, 130, 6064-6079. [CrossRef] [PubMed]

37. Varga-Szabo, D.; Braun, A.; Nieswandt, B. Calcium signaling in platelets. J. Thromb. Haemost. 2009, 7, 1057-1066. [CrossRef] 
38. Boylan, B.; Gao, C.; Rathore, V.; Gill, J.C.; Newman, D.K.; Newman, P.J. Identification of FcgammaRIIa as the ITAM-bearing receptor mediating alphaIlbbeta3 outside-in integrin signaling in human platelets. Blood 2008, 112, 2780-2786. [CrossRef] [PubMed]

39. Phillips, D.R.; Nannizzi-Alaimo, L.; Prasad, K.S. Beta3 tyrosine phosphorylation in alphaIIbbeta3 (platelet membrane GP IIb-IIIa) outside-in integrin signaling. Thromb. Haemost. 2001, 86, 246-258. [PubMed] 